possible target applications, as well as a correspondingly large, interested U.S. and international industrial base for functionally graded structural materials.

\section{Acknowledgments}

The authors thank Dr. G.B. Kenney, Prof. L. Kimerling, and other staff members of the Materials Processing Center at
MIT; and Drs. S.G. Fishman and A.K. Vasudevan of the Office of Naval Research for their support and help in organizing this workshop.

\section{References}

1. Functionally Graded Structural Materials, edited by S. Suresh, A. Mortensen, and $\mathrm{H}$. McManus, workshop brief from The
Materials Processing Center, MIT, Cambridge, MA, March 1994.

S. SURESH, A. MORTENSON, AND H. MCMANUS

For information on S. Suresh, A. Mortenson, and $H$. McManus, please see the author biographies on pages 15-18.

\title{
SAM'95 Meeting in Argentina Features Magnetic Materials
}

The Materials Argentine Association (SAM) is sponsoring the SAM'95 Meeting and the First Argentine Workshop on Magnetic Materials and Their Applications in "Centro di Materiales y Metrologia" in Cordoba, Argentina, May 17-20, 1995.

The SAM'95 Meeting promotes links between scientists, professionals, technicians and industrialists who develop their activities in the materials field, facilitating the divulging and spreading of their work results through the various specialized sessions. This year's meeting emphasizes the magnetic materials field.

The sessions will consist of 10 -minute oral presentations followed by 5 -minute discussions. Plenary sessions, with the participation of specialists from all over the world, and Techno-Commercial sessions are also planned. The meeting will cover the following areas:

1. Extractive and Manufacturing Metallurgy

2. Melting, Solidification, and Welding

3. Physical Metallurgy

4. Plastic Deformation and Welding

5. Thermal Treatments and Phase Transformations

6. Fracture and Fatigue

7. Corrosion and Protection Methods

8. Defects Analysis

9. Special Tests and Techniques

10. New Materials

11. Biomaterials

12. Ceramics and Refractories

13. Pulvimetallurgy

14. Polymers. Composites

15. Tribology

16. Technology Management and Human Resources

17. Historic Metallurgy
The Workshop on Magnetic Materials will feature:

1. Magnetic Materials Processing. Raw Materials

2. Magnetic Properties

3. Models and Mechanisms

4. Measurement Systems. Standardization

5. Magnetic Circuit Design. Applications

6. Electromagnetic Interferences. Bioapplications. RMN

At the end of the meeting several awards will be given to researchers belonging to Latinoamerican University Laboratories: Jorge Sabato Award-Best Work of Technological Development; Jorge Kittl Award-Best Work of Research; Best Work on Steels Award; Best Work on Aluminum Award; and Best Work on Research or Technological Development Initiation Award.

For more information contact Ing. Raul Barbosa; "Jornadas SAM'95" Executive Secretary; CIMM; Av. Velez Sarsfield 1561; P.O. Box 884; 5000 Cordoba, Argentina; (Fax: 54-51-69-9459).

\section{Ine Milf Bulldelin -}

A grpet Wey] tojuin Milit

[if you haven't alpradty.

\section{Monthly subscription FREE with your membership!}

Regular Members: $\$ 75$
Student Members: $\$ 25$

$\mathrm{M}|\mathrm{R}| \mathrm{S}$

Contact: Materials Research Society

9800 McKnight Road, Pittsburgh, PA 15237

Phone: (412) 367-3004, x-402; Fax: (412) 367-4373

E-mail: INFO@MRS.ORG 